\title{
Genome size as a predictor of guard cell length in Arabidopsis thaliana is independent of environmental conditions
}

\author{
Barry H. Lomax, F. Ian Woodward, Ilia J. Leitch, Charles A. Knight \\ and Janice A. Lake
}

\section{Summary}

- The recent discovery of a strong positive relationship between angiosperm genome size and stomatal guard cell length (GCL) opens the possibility of using plant fossil guard cell size as a proxy for changes in angiosperm genome size over periods of environmental change.

- The responses of GCL to environmental stimuli are currently unknown and may obscure this predictive relationship.

- Here, we investigated the effects of environmental variables (atmospheric $\mathrm{CO}_{2}$, drought, relative humidity, irradiance, ultraviolet radiation and pathogen attack) on GCL in the model plant Arabidopsis thaliana to quantify environmentally induced variation.

- GCL responded to all variables tested, but the changes incurred did not significantly impinge on the predictive capability of the relationship.

Key words: angiosperm genome size, Arabidopsis thaliana, carbon dioxide $\left(\mathrm{CO}_{2}\right)$, guard cell length $(\mathrm{GCL})$, irradiance, pathogen, relative humidity, UV-B.

\section{Introduction}

The study of stomatal responses to the environment has played a central role in plant science research over the last $80 \mathrm{yr}$ (Salisbury, 1928). One of the most exciting areas of stomatal research to recently emerge suggests that the genome size of angiosperms is a strong, positive predictor of guard cell length (GCL) (Beaulieu et al., 2008). This study, which covered a phylogenetically diverse sample of angiosperms, across varying growth forms (monocots, eudicots, trees, shrubs and herbs), supports the early work of Masterson (1994) whose data suggested that the small guard cell size of Cretaceous angiosperms was indicative of a small genome (Leitch, 2007). These published findings open the intriguing possibility of using the fossil angiosperm GCL record to track evolutionary changes in the size of a plant's genome over geological time, analogous to the studies of Thomson (1972), Conway Morris \& Harper (1988) and Organ et al. (2007) in animals.

It is well known that stomatal density (SD) and index (SI) (the ratio of the number of stomata to the number of epidermal cells) are sensitive to atmospheric $\mathrm{CO}_{2}$ concentrations (Woodward, 1987) and primarily controlled by transpiration rate and in vivo abscisic acid concentration (Lake \& Woodward, 2008). SD and SI are also sensitive to the intensity of incident radiation (Lake et al., 2001; Thomas et al., 2003). However, to date little is known about how these environmental variables influence GCL.

Atmospheric $\mathrm{CO}_{2}$ is predicted to have varied considerably over geological time since the origin and diversification of 
land plants (Wellman et al., 2003), from -4000 to 280 parts per million (ppm) (Berner \& Kothavala, 2001), and catastrophic climate change and mass extinction events have been linked to rapid increases in $\mathrm{CO}_{2}$ (Lomax et al., 2000; Beerling et al., 2002). In addition to these long-term changes, analysis of the palaeobotanical record and geochemical modelling indicates that, at certain periods, the Earth's terrestrial flora may have been periodically exposed to prolonged and extreme increases in the flux of ultraviolet-B (UV-B) radiation (Visscher et al., 2004; Beerling et al., 2007) and intense periods of fungal attack (Visscher et al., 1996), both environmental stimuli that have been recently shown to alter GCL (J. A. Lake, unpublished).

Consequently, before direct measurements of fossil guard cell size can be used with confidence as a proxy for the palaeoplant genome, it is necessary to investigate the role of these environmental stimuli under experimental conditions. This study begins to address these uncertainties by quantifying the effects that environmental stimuli falling within geologically relevant ranges $\left(\mathrm{CO}_{2}\right.$ concentration, UV-B radiation and pathogen attack) and ecologically relevant ranges (water availability, relative humidity and photosynthetically active radiation (PAR)) have on the GCL of Arabidopsis thaliana. The stomatal density response of $A$. thaliana to a doubling of atmospheric $\mathrm{CO}_{2}$ is representative of the responses seen in 110 species (Woodward et al., 2002) and $A$. thaliana is therefore viewed as an ideal model plant with which to investigate the environmental controls of GCL. The most recently revised genome size for $A$. thaliana is reported to be $1 \mathrm{C}=157$ Mega basepairs (Mb) (Bennett et al., 2003).

\section{Materials and Methods}

\section{$\mathrm{CO}_{2}$ concentration and water availability}

Seeds of Arabidopsis thaliana (L.) Heynh. (ecotype Columbia (Col-0)) were sown onto multipurpose compost (Arthur Bowyers, William Sinclair Horticulture Ltd, Lincoln, UK) covered with plastic film and stratified for $3 \mathrm{~d}$ at $4^{\circ} \mathrm{C}$. They were then transferred into growth cabinets (Fitotron Model SGC097.PPX.F; Sanyo Gallenkamp, Loughborough, UK) and grown under a day:night regime of $8: 16 \mathrm{~h}$ at $25: 21 \pm 0.5^{\circ} \mathrm{C}$ and $55 \%$ relative humidity $(\mathrm{RH})$. Seven separate $\mathrm{CO}_{2}$ experiments were conducted, with $\mathrm{CO}_{2}$ held at geologically relevant (Berner \& Kothavala, 2001) concentrations of 400, 760, 1000, 1500, 2000 and $3000 \mathrm{ppm}$. Nested within each $\mathrm{CO}_{2}$ treatment, plants at the 4-wk stage were also subjected to one of three watering regimes, drought $\left(10 \mathrm{ml} \mathrm{d}^{-1}\right)$ well watered (20-30 $\mathrm{ml} \mathrm{d}^{-1}$ ) and saturated (constantly wet compost).

\section{Relative humidity}

Plants were germinated and stratified as above, transferred into growth cabinets (Fitotron Model SGC097.PPX.F; Sanyo
Gallenkamp) and grown under a day:night regime of $8: 16 \mathrm{~h}$ at $22: 18 \pm 0.5^{\circ} \mathrm{C}$ and either 45 or $85 \% \mathrm{RH}$.

\section{Incident (PAR) radiation}

Plants were germinated and stratified as above, transferred to controlled-environment chambers and grown under a day:night cycle of $14: 10 \mathrm{~h}, 25: 18 \pm 0.5^{\circ} \mathrm{C}$ and $\mathrm{RH} 50 \pm 3 \%$ at different distances from the light source, producing a range of PAR values: 22, 33, 45, 60 and $83 \mu \mathrm{mol} \mathrm{m}^{-2} \mathrm{~s}^{-1}$ (Fitotron SGC970/ P/FL; Sanyo Gallenkamp), and 100, 340 and $500 \mu \mathrm{mol} \mathrm{m}^{-2} \mathrm{~s}^{-1}$ (Conviron BDR16; Conviron, Winnipeg, Canada).

\section{UV-B radiation}

Plants were germinated and stratified as above, transferred into growth cabinets (Model P61700H/FM/RO-HQI; Sanyo Gallenkamp) and grown under a day:night regime of $8: 16 \mathrm{~h}$ at $21: 15^{\circ} \mathrm{C}, 60 \% \mathrm{RH}$, and vapour pressure deficit (VPD) $0.995 \mathrm{kPa}$. UV-B light was supplied by a bank of nine Sanolux UV high-pressure lamps (323 1219; Phillips, Guildford, UK) which increased UV-B (measured at $300 \mathrm{~nm}$ ) radiation to $26 \pm 0.01 \mathrm{~kJ} \mathrm{~m}^{-2} \mathrm{~d}^{-1}$ at plant height over the entire daylength; in the control cabinet all UV-B radiation was excluded and UV-A radiation was reduced using using specific UV-B and UV-A cut-off wavelength filters (226 Lee U.V.; Lee Filters, Andover, UK). UV-B levels were measured using a Sola-Check System (Solatell Ltd, Croydon, UK), crosscalibrated with a Macam spectroradiometer (SR9000-V7; Macam Photometrics Ltd, Livingston, UK).

\section{Pathogen challenge}

Plants were germinated and stratified as above and transferred to controlled-environment chambers (Fitotron SGC2352/ FM/HFL; Sanyo Gallenkamp) and grown under a day:night regime of $8: 16 \mathrm{~h}$ at $22: 18 \pm 0.5^{\circ} \mathrm{C}, 150 \mu \mathrm{mol} \mathrm{m}^{-2} \mathrm{~s}^{-1}$ irradiance, and $55 \pm 5 \% \mathrm{RH}$. Actively growing cultures of Erysiphe cichoracearum were maintained on marrow (Cucurbita pepo L. cv. Long Green Bush). Inoculum was applied at the 7- to 10-d stage. At the 4-wk stage (10 rosette leaves present) leaf insertions $6-10$ were painted with inoculum at a spore concentration of $1 \times 10^{5} \mathrm{ml}^{-1}$ in a suspension of Fluorinert (Sigma-Aldrich, Gillingham, UK); control plants were painted with Fluorinert only. Plants (both infected and control) were enclosed in propagators to isolate inoculated from control plants held within the same controlled-environment chamber and to raise humidity to $80-85 \%$ for effective infection. Seven days later, leaf insertions 14-17 were harvested for GCL analyses.

\section{Stomatal guard cell analyses}

For all treatments, five replicates were grown under each condition, from which three fully mature leaves were harvested 

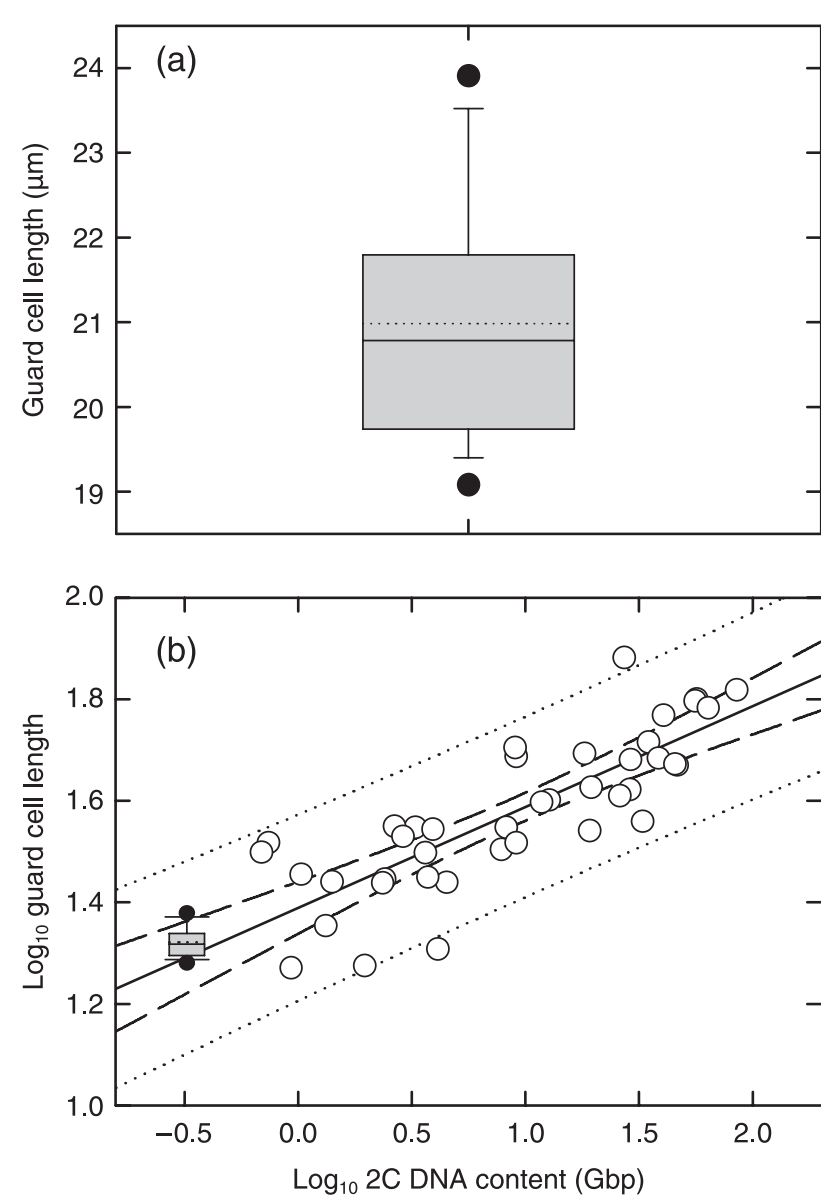

Fig. 1 Arabidopsis thaliana guard cell length (GCL) and genome size. (a) Box and whiskers plot of the range of GCLs; the box plot represents the median (solid line), mean (dotted line), and 25th and 75th percentiles (grey box); the whiskers are the 5th and 95th percentiles and the outliers are solid circles. (b) $\log _{10}$-transformed GCL compared with the herb data set of Beaulieu et al. (2008). The solid line is the linear regression $\left(y=0.1987 x+1.3894 ; r^{2}=0.66\right.$; $F=+77.3268 ; P<0.0001)$, the dashed line the $95 \%$ confidence limits and dotted line the $95 \%$ prediction limits.

for GCL analysis. Epidermal impressions of the abaxial leaf surface were made using standard techniques developed in Sheffield (Coupe et al., 2005). Twenty-one stomata per leaf were sampled per treatment to derive an average GCL; all measurements were taken using image analysis software (Quantimet 500C image analysis system; Leica Instruments, Cambridge, UK) coupled to a light microscope (Leitz Laborlux S; Leica Microsystems, Milton Keynes, UK) at ×400 magnification.

\section{Results and Discussion}

Changes in GCL occurred in response to all environmental stimuli investigated. The smallest change in GCL (an increase of $3 \%$ ), calculated as a percentage change of the full range (i.e. minimum to maximum) mean value, occurred when $\mathrm{RH}$ was raised from 45 to $85 \%$. Increases in $\mathrm{CO}_{2}$ from 380 to
$3000 \mathrm{ppm}$ and in water availability from $10 \mathrm{ml} \mathrm{d}^{-1}$ to continually saturated soil both resulted in a $6 \%$ increase in GCL. High levels of UV-B caused a 7\% increase in GCL, while pathogen challenge increased GCL by $10 \%$ compared with uninfected control leaves. Reducing incident PAR to values analogous to those measured in the lowest $20 \mathrm{~m}$ of rainforest canopies $\left(22-83 \mu \mathrm{mol} \mathrm{m}{ }^{-2} \mathrm{~s}^{-1}\right.$; Torquebiau, 1988) produced the largest response, an 18\% decrease from 83 to $22 \mu \mathrm{mol} \mathrm{m}^{-2} \mathrm{~s}^{-1}$ in GCL (Table 1, Fig. 1a).

$\log _{10}$ transformation of this data set (Fig. 1b) allows direct comparison with the work of Beaulieu et al. (2008). A C value of $157 \mathrm{Mb}$ for $A$. thaliana (Bennett et al., 2003) translates into a $\log _{10} 2 \mathrm{C}$ value of -0.503 Giga base pairs (Gbp). The box plot (Fig. 1b) of the $\log _{10}$-transformed GCL shows a close correspondence to the herb data set of Beaulieu et al. (2008) with the median, mean, and 5th, 25th and 75 th percentiles plotting inside the confidence limits of the regression, with only the 95th percentile and the upper outlier plotting outside these limits, but well within the prediction limits of the data (Fig. 1b, Table 1).

Both the 95th percentile and the upper outlier are associated with extreme irradiance environments; high chronic UV-B radiation and very low PAR, respectively. The relatively large increases in GCL observed in A. thaliana when grown in experimental conditions simulating deep shade suggest that low light intensities may result in an overestimation of the size of the fossil plant genome. However, as a whole, the leaf fossil record tends to be biased towards the preservation of sun rather than shade leaves (Spicer, 1981); furthermore, leaf epidermal cell features can be used to distinguish between sun and shade leaves (Kurschner, 1997; Thomas et al., 2003). Chronic high levels of UV-B radiation may also lead to an overestimation of the size of the fossil plant genome. However, to date, evidence for a collapse in the Earth's protective ozone layer is restricted to the Permo-Triassic boundary mass extinction event, suggesting that high fluxes of UV-B radiation are relatively rare.

Overall, the narrow range in GCLs, given the wide spread of environmental conditions and the closeness of fit between the herb (Beaulieu et al., 2008) and A. thaliana data sets (Fig. 1b), provides evidence that environmental perturbations do not impinge significantly on the overall predictive quality of the relationship between GCL and genome size in this species. GCL values fall well within the predictive intervals of the linear regression (Table 1). The low sensitivity of GCL to the broad range of atmospheric $\mathrm{CO}_{2}$ concentrations investigated here suggests that changes in fossil GCL may be used as a proxy to track changes in plant genome size over evolutionary time and give an insight into how plant genomes have responded to climatic catastrophe.

\section{Acknowledgements}

BHL was funded through a Leverhulme Trust Early Career Fellowship (ECF/2006/0492) and JAL through a Royal Society Dorothy Hodgkin Fellowship. This study was supported by a 
Table 1 The range (minimum and maximum) of guard cell size measured under different environmental conditions together with $95 \%$ prediction and confidence intervals from Fig. 1

\begin{tabular}{|c|c|c|c|c|}
\hline Environmental variable & $\begin{array}{l}\text { Minimum } \\
(\mu \mathrm{m})\end{array}$ & $\begin{array}{l}\text { Minimum } \\
\text { (log value) }\end{array}$ & $\begin{array}{l}\text { Maximum } \\
(\mu \mathrm{m})\end{array}$ & $\begin{array}{l}\text { Maximum } \\
\text { (log value) }\end{array}$ \\
\hline $95 \%$ prediction intervals & 12.90 & 1.1108 & 28.00 & 1.4773 \\
\hline $95 \%$ confidence intervals & 16.18 & 1.2090 & 22.64 & 1.3550 \\
\hline $\mathrm{CO}_{2}$ concentration & 20.58 & 1.3135 & 21.84 & 1.3393 \\
\hline Drought & 19.74 & 1.2954 & 20.98 & 1.3219 \\
\hline Relative humidity & 20.53 & 1.3126 & 21.16 & 1.3257 \\
\hline $\begin{array}{l}\text { Incident PAR (low) } \\
22-87 \mu \mathrm{mol} \mathrm{m}^{-2} \mathrm{~s}^{-1}\end{array}$ & 19.72 & 1.2949 & 23.91 & 1.3787 \\
\hline $\begin{array}{l}\text { Incident PAR (high) } \\
100-500 \mu \mathrm{mol} \mathrm{m}^{-2} \mathrm{~s}^{-1}\end{array}$ & 19.08 & 1.2808 & 19.96 & 1.3003 \\
\hline UV-B radiation & 21.64 & 1.3354 & 23.14 & 1.3645 \\
\hline Pathogen challenge & 19.72 & 1.2949 & 21.78 & 1.3382 \\
\hline
\end{tabular}

PAR, photosynthetically active radiation; UV, ultraviolet.

University of Sheffield Biology Division Small Grant to BHL and JAL. We thank Nicola Hurst, Sarah Wardell and Judith Foulkes for data collection.

\section{References}

Beaulieu JM, Leitch IJ, Patel S, Pendharkar A, Knight CA. 2008. Genome size is a strong predictor of cell size and stomatal density in angiosperms. New Phytologist 179: 975-986.

Beerling DJ, Harfoot M, Lomax BH, Pyle JA. 2007. The stability of the stratospheric ozone layer during the end-Permian eruption of the Siberian Traps. Philosophical Transactions of the Royal Society A 365: 1843-1866.

Beerling DJ, Lomax BH, Royer DL, Upchurch GR, Kump LR. 2002. An atmospheric $\mathrm{pCO}_{2}$ reconstruction across the Cretaceous-Tertiary boundary from leaf megafossils. Proceedings of the National Academy of Sciences, USA 99: 7836-7840.

Bennett MD, Leitch IJ, Price HJ, Johnston JS. 2003. Comparisons with Caenorhabditis $(-100 \mathrm{Mb})$ and Drosophila $(\sim 175 \mathrm{Mb})$ using flow cytometry show genome size in Arabidopsis to be $\sim 157 \mathrm{Mb}$ and thus $\sim 25 \%$ larger than the Arabidopsis Genome Initiative estimate of $\sim 125 \mathrm{Mb}$. Annals of Botany 91: 547-557.

Berner RA, Kothavala Z. 2001. Geocarb III: a revised model of atmospheric $\mathrm{CO}_{2}$ over Phanerozoic time. American Journal of Science 301: 182-204.

Conway Morris S, Harper E. 1988. Genome size in Conodonts (Chordata): inferred variation during 270 million years. Science 241: 1230-1232.

Coupe SA, Palmer BG, Lake JA, Overy SA, Oxborough K, Gray JE, Quick WP. 2005. Systemic signalling of environmental cues in Arabidopsis leaves. Journal of Experimental Botany 57: 329-341.

Kurschner WM. 1997. The anatomical diversity of recent and fossil leaves of the durmast oak (Quercus petraea Lieblein/Q. pseudocastanea Goeppert): implications for their use as biosensors of palaeoatmospheric $\mathrm{CO}_{2}$ levels. Review of Palaeobotany and Palynology 96: 1-30.

Lake JA, Quick WP, Beerling DJ, Woodward FI. 2001. Plant development - signals from mature to new leaves. Nature 411: 154.

Lake JA, Woodward FI. 2008. Response of stomatal numbers to $\mathrm{CO}_{2}$ and humidity: control by transpiration rate and abscisic acid. New Phytologist 179: $397-404$
Leitch IJ. 2007. Genome sizes through the ages. Heredity 99: 121-122.

Lomax BH, Beerling DJ, Upchurch GR, Otto-Bliesner BL. 2000.

Terrestrial ecosystem responses to global environmental change across the Cretaceous-Tertiary boundary. Geophysical Research Letters 27: $2149-2152$.

Masterson J. 1994. Stomatal size in fossil plants - evidence for polyploidy in majority of angiosperms. Science 264: 421-424.

Organ CL, Shedlock AM, Meade A, Pagel M, Edwards SV. 2007. Origin of avian genome size and structure in nonavian dinosaurs. Nature 446: $180-184$.

Salisbury EJ. 1928. On the causes and ecological significance of stomatal frequency, with special reference to the woodland flora. Philosophical Transactions of the Royal Society of London Series B 216: 1-65.

Spicer RA. 1981. The sorting and deposition of allochthonous plant material in a modern environment at Silwood Lake, Silwood Park, Berkshire, England. US Geological Survey Professional Papers 1143: 77.

Thomas PW, Woodward FI, Quick WP. 2003. Systemic irradiance signalling in tobacco. New Phytologist 161: 193-198.

Thomson KS. 1972. An attempt to reconstruct evolutionary changes in the cellular DNA content of lungfish. Journal of Experimental Zoology 180: 363-372.

Torquebiau EF. 1988. Photosynthetically active radiation environment: Patch dynamics and architecture in a tropical rainforest in Sumatra. Australian Journal of Plant Physiology 15: 327-342.

Visscher H, Brinkhuis H, Dilcher DL, Elsik WC, Eshet Y, Looy CV, Rampino MR, Traverse A. 1996. The terminal paleaozoic fungal event: evidence of terrestrial ecosystem destabilization and collapse. Proceedings of the National Academy of Sciences, USA 93: 2155-2158.

Visscher H, Looy CV, Collinson ME, Brinkhuis H, Van Cittert JHA, Kurschner WM, Sephton MA. 2004. Environmental mutagenesis during the end-Permian ecological crisis. Proceedings of the National Academy of Sciences, USA 101: 12952-12956.

Wellman CH, Osterloff PL, Mohiuddin U. 2003. Fragments of the earliest land plants Nature 425: 282-285.

Woodward FI. 1987. Stomatal numbers are sensitive to increases in $\mathrm{CO}_{2}$ from pre-industrial levels. Nature 327: 617-618.

Woodward FI, Lake JA, Quick WP. 2002. Stomatal development and $\mathrm{CO}_{2}$ : ecological consequences. New Phytologist 153: 477-484. 